\title{
Desenhando a nova morfologia do trabalho no Brasil
}

\author{
RICARDO ANTUNES ${ }^{I}$
}

\section{A classe trabalhadora na particularidade do capitalismo brasileiro}

$\mathrm{P}$ OUCAS décadas atrás, impulsionada por uma forte tendência eurocêntrica, a ideia de que a classe trabalhadora estava em franca redução tornou-se quase um novo dogma. Dos Estados Unidos aos principais países da Europa, o mito de um capitalismo maquínico e sem trabalho se expandia, conseguindo adeptos em várias partes do mundo. E se era possível visualizá-lo movido quase que exclusivamente pela técnica, só restava mesmo sepultar a classe trabalhadora, fazendo-lhe um réquiem.

Se essa ideia era no mínimo bastante problemática nos países do norte, como deixar de considerar o monumental contingente de trabalho existente no sul do mundo, especialmente em países como China, Índia e tantos países asiáticos de industrialização recente. Ou ainda Brasil, México, dentre tantos outros exemplos latino-americanos dotados de grande contingente de força de trabalho?

Se é verdade que a produção (em sentido amplo) vem se metamorfoseando significativamente a partir da introdução do universo informacional-digital, seria plausível, então, conceber a possibilidade real de um capitalismo sem trabalho? E mais, seria ainda possível equalizar países com realidades tão díspares, borrando as mais diferenciadas formas pelas quais se apresenta a divisão internacional do trabalho?

Ao contrário dessas formulações, nosso exercício empírico e analítico tem se pautado pela tentativa de oferecer uma melhor intelecção dessa problemática, buscando uma melhor compreensão de quem é a classe trabalhadora hoje, resultado de um monumental processo de reestruturação produtiva desencadeado desde os inícios dos anos 1970 nos países centrais, e especialmente desde meados dos anos 1980 nos países do sul. Qual é sua nova morfologia, seu novo desenho, sua conformação? E como é possível, a partir desse novo desenho, desconstruir e contraditar empírica e analiticamente as teses que propugnavam a "perda de relevância" do trabalho?

Se parece evidente que o proletariado industrial, herdeiro da era taylorista e fordista, vem se reduzindo em várias partes do mundo capitalista central, há também uma contratendência forte, dada pela expansão exponencial de novos contingentes de trabalhadores ${ }^{1}$ e trabalhadoras especialmente no setor de serviços, mas também na agroindústria e, ainda que em menor intensidade, na indústria. Basta olhar, por exemplo, para a China e a Índia nas últimas duas décadas. 
Esse nosso texto pretende, então, apresentar algumas tendências que particularizam a nossa classe trabalhadora. Sabemos que as mudanças e transformações ocorridas no capitalismo recente, a partir de meados da década de 1980 e especialmente na década seguinte, foram de grande intensidade e desencadearam um conjunto de transformações, alterando, em alguma medida, elementos da forma de ser da classe trabalhadora. O Brasil se estruturava, então, com base em um desenho produtivo bifronte: de um lado, era voltado para a produção de bens de consumo duráveis, como automóveis, eletrodomésticos etc., visando um mercado interno restrito e seletivo; de outro, dada sua condição de dependência em relação ao capitalismo avançado, desenvolvia a produção voltada para a exportação, tanto de produtos primários quanto de produtos industrializados.

Internamente, a dinâmica do padrão de acumulação capitalista se baseava na vigência de um processo de superexploração da força de trabalho, caracterizado por baixos salários, ritmos de produção intensificados, jornadas de trabalho prolongadas, combinando uma extração tanto da mais valia absoluta quanto da mais valia relativa. E esse padrão de acumulação gerou altas taxas de acumulação, de que foi exemplo o chamado "milagre econômico" (1968-1973). Com a vitória do neoliberalismo no Brasil, a partir de 1990, ampliou-se o processo de reestruturação produtiva, mediante a adoção de novos padrões organizacionais e tecnológicos, de novas formas de organização do trabalho e da introdução dos métodos "participativos", em decorrência das imposições das empresas transnacionais que levaram as suas subsidiárias no Brasil a adotar, em maior ou menor medida, técnicas inspiradas no toyotismo e nas formas flexíveis de acumulação. As empresas brasileiras tiveram que se adaptar à competitividade internacional, sem deixar de responder às ações sindicais praticadas pelo "novo sindicalismo", emergente especialmente a partir da eclosão das greves do ABC no pós-1978 (Antunes, 2006 e 2013; Alves, 2000).

Combinando elementos herdeiros do fordismo (vigentes em vários ramos e setores produtivos) com uma nova pragmática pautada pela acumulação flexível, pela empresa enxuta (lean production), pela implantação de programas de qualidade total e sistemas just-in-time e kanban, além da introdução de ganhos salariais vinculados à lucratividade e à produtividade (como o PLR, programa de participação nos lucros e resultados), sob uma pragmática que se adequava fortemente aos desígnios do capital financeiro e do ideário neoliberal, tudo isso acabou possibilitando uma reestruturação produtiva de grande intensidade no Brasil, que teve como consequências a ampliação da flexibilização, da informalidade e da precarização da classe trabalhadora.

Se a informalidade (que em nosso entendimento ocorre quando o contrato de trabalho não obedece à legislação social protetora do trabalho) não é sinônimo de precarização, sua vigência (da informalidade) amplia e intensifica ainda mais o processo de precarização. $\mathrm{E}$ os mais diversos mecanismos de flexibilização do trabalho têm sido importante instrumental utilizado pelas empresas para burlar a legislação social do trabalho. 
A expansão das empresas de call centers e telemarketing e das empresas de Tecnologias de Informação e Comunicação (TIC), cada vez mais imprescindíveis para a redução do tempo de circulação do capital, acabou por incentivar a expansão de um novo proletariado de serviços, o infoproletariado (Antunes; Braga, 2009) ou o cybertariat, na feliz definição de Úrsula Huws (2003). Assim, em plena era da informatização do trabalho no mundo maquinal-digital, vem ocorrendo também um processo contraditório, marcado pelo aumento da informalização do trabalho, presente na ampliação dos terceirizados, subcontratados, flexibilizados, em tempo parcial, teletrabalhadores, ampliando o universo do trabalho precarizado.

A flexibilização produtiva, as desregulamentações, as novas formas de gestão do capital, a ampliação das terceirizações e da informalidade acabaram por desenhar uma nova fase do capitalismo no Brasil. As novas modalidades de exploração intensificada do trabalho, combinadas com um relativo avanço tecnológico em um país dotado de um enorme mercado consumidor tornaram-se elementos centrais da produção capitalista no Brasil. A articulação complexa existente entre financeirização da economia, neoliberalismo, reestruturação produtiva e as mutações no espaço microcósmico do trabalho e da empresa não poderia deixar de afetar profundamente a classe trabalhadora.

Se na década de 1990 tivemos um período de forte redução nos empregos formalizados, ${ }^{2}$ na década de 2000 foram criados 21 milhões de postos de trabalho, dos quais $94,8 \%$ percebiam uma baixa remuneração ( 1,5 salário mínimo por mês). As atividades nos serviços geraram 6,1 milhões de empregos; seguidas pelos trabalhadores do comércio com 2,1 milhões; da construção civil com 2 milhões; de escriturários com 1,6 milhão; da indústria têxtil e vestuário, com 1,3 milhão; e do setor público com 1,3 milhão. Como afirma Marcio Pochmann (2012, p.32), essas profissões totalizaram 14,4 milhões de novos postos de trabalho, compreendendo $72,4 \%$ de todas as ocupações com remuneração também de até 1,5 salário mínimo mensal. Vale acrescentar também que foi significativa a ampliação do trabalho feminino, chegando a quase $60 \%$ das ocupações, e, no que diz respeito à faixa etária, a maior parte concentrou-se na faixa de 25 a 34 anos.

Se ao longo da década de 1980 era relativamente pequeno o número de terceirizados (subcontratados), nas décadas seguintes esse número aumentou significativamente, trabalhadores frequentemente sem vínculo empregatício e sem registro formalizado, por vezes à margem da legislação trabalhista, redesenhando a morfologia do trabalho no Brasil (Druck, 1999, 2011; Druck; Franco, 2007).

\section{Elementos para uma fenomenologia da superexploração do trabalho: alguns exemplos emblemáticos ${ }^{3}$}

Vamos, então, apresentar alguns resultados de pesquisa de três setores distintos e emblemáticos, que cumprem papel de destaque no capitalismo brasileiro: a indústria metalúrgica, a agroindústria e o setor de serviços de telemarketing e call center. 
Começaremos com a indústria automobilística, na qual encontramos o proletariado industrial herdeiro, em maior ou menor medida, da fase de vigência do taylorismo-fordismo no Brasil. Em seguida apresentaremos dimensões do trabalho no agronegócios e, por fim, do proletariado de serviços (call center e telemarketing) que se expandiu exponencialmente na era da financeirização e privatização neoliberal no Brasil.

\section{A induistria automobilistica}

$\mathrm{Na}$ pesquisa junto à indústria automotiva, realizada por Luci Praun (2014), ${ }^{4}$ com trabalhadores da General Motors do Brasil (GMB), na unidade produtiva instalada no município de São José dos Campos $(\mathrm{SP}),{ }^{5}$ os principais resultados indicaram a clara articulação entre as diferentes formas de exploração do trabalho, causadas pela aceleração intensa dos ritmos e pela intensificação da atividade laborativa, acarretando alta incidência de acidentes e de adoecimentos do trabalho, especialmente a partir de 2008, quando a GM, em decorrência da profunda crise em que se encontrava, desencadeou uma nova fase de implantação do seu Sistema Global de Manufatura. No contexto de crise, a empresa aumentou a integração dos processos produtivos das diversas unidades, em escala global, e os resultados mais imediatos foram: fechamento de unidades produtivas e demissão de trabalhadores, além da realocação e transferência de atividades entre as diversas unidades produtivas da GM.

Esse processo se efetivou através de: 1) demissões diretas ou por meio de Planos de Demissão Voluntária (PDV); 2) novos pisos salariais reduzidos; 3 ) maior ritmo e intensidade do trabalho, com a introdução de novos mecanismos de medição e padronização de atividades, com o objetivo de redução do tempo das operações; 4) maior robotização do processo produtivo; e) intensificação de sistemas de metas e resultados, com destaque para a Participação nos Lucros e Resultados (PLR), além de maior controle nos sistemas de avaliação, individuais ou das equipes de trabalho.

A diferenciação salarial e de condições de trabalho também tem sido, como destaca Luci Praun (2014), uma importante característica do setor metalúrgico, diferenciação não só entre países que compõem a cadeia produtiva global da GM, mas também dentro do Brasil, através das diferenciações regionais, maior ou menor organização e resistência sindical etc. O Quadro l é elucidativo das diferenças salariais existentes nas três unidades produtivas da GM no Brasil.

Assim como as diferenciações salariais, há por parte da GM uma prática intensificada de redução do "tempo morto" de trabalho, através da reorganização dos ciclos de operações. Um exemplo pode ser encontrado no ciclo de operações de fixação dos freios ABS em picapes S10, executado em 175 segundos (Actual Takt Time), mas que, depois da reorganização, trouxe uma redução de quase $30 \%$ no tempo de execução. Do mesmo modo, uma mudança nos sistemas computadorizados de projeção e execução do processo produtivo foi realizada pela GM, acarretando maior intensificação do trabalho. São claras as palavras do 
vice-presidente de manufatura da GM América do Sul: "Graças à tecnologia e ao processo de melhorias contínuas, podemos ganhar um segundo a mais, dois segundos a mais no ciclo de cada veículo". E acrescenta: "Para se ter uma ideia da importância disso, em Gravataí, que tem capacidade para 360 mil unidades por ano, ganhar um segundo, só nas operações de gargalo da produção, significa 7 mil carros a mais por ano" (apud Praun, 2014, p.113).

Quadro 1 - Renda média trabalhadores General Motors (em R\$)

\begin{tabular}{l|c|c|c}
\hline & $\begin{array}{c}\text { São Caetano } \\
\text { do Sul }\end{array}$ & $\begin{array}{c}\text { São José } \\
\text { dos Campos }\end{array}$ & Gravataí \\
\hline 2012 & $5.996,19$ & $4.813,21$ & $2.505,43$ \\
\hline 2011 & $6.223,66$ & $4.928,22$ & $2.549,64$ \\
\hline 2010 & $6.883,78$ & $4.851,84$ & $2.643,27$ \\
\hline 2009 & $6.725,46$ & $4.751,31$ & $2.569,74$ \\
\hline 2008 & $5.906,93$ & $4.628,50$ & $2.666,82$ \\
\hline
\end{tabular}

Fonte das informações: Dieese, 2012 (Praun, 2014).

A intensificação do trabalho foi constatada no depoimento do operário Alex Gomes, representante da Comissão Interna de Prevenção de Acidentes (Cipa), na fábrica da GM de São José dos Campos (SP):

Esse aumento dessa pressão interna na fábrica, o trabalhador com medo de ser mandado embora, ele trabalha o tempo todo com esse pavor na cabeça, que é um clima de terror. A gente vive um clima constante de terror. Depois de 2011 só se agravou. O cara entra todo dia na fábrica achando que vai ser demitido. Isso tira a atenção dele na hora de fazer o trabalho, aumenta a incidência, isso gera um risco maior de acidente. (apud Praun, 2014, p.72)

Em relação às avaliações de desempenho, o depoimento acrescenta ainda que:

Todo ano, na semana do aniversário do trabalhador, ele é chamado pela supervisão para fazer o $\mathrm{PAD}$, que é o Plano de Análise de Desempenho. Ali tem uma série de avaliações, de assiduidade, de resposta à qualidade. Se o cara em um ano tem uma questão de produzir menos, produzindo defeito, isso tudo entra na avaliação. E aí é feita uma conversa do supervisor com o CT [Coordenador de Time] da pessoa. Ele é chamado na mesa. O supervisor passa tudo aquilo para ele: "você está ruim nisso aqui, está ruim naquilo ali" e dá para o trabalhador assinar. (apud ibidem, p.59)

A GM também realiza avaliações da equipe de trabalho, onde os resultados são apresentados por meio de bolas coloridas afixadas ao lado de cada equipe: bola verde significa que a produção está normal; bola amarela, é preciso melho- 
rar; e bola vermelha quer dizer que a produção está abaixo do esperado. E essa forma de avaliação do desempenho, além da obrigar a uma maior intensidade e ritmo de produção, provoca uma divisão ainda maior entre os trabalhadores (mais produtivos e mais improdutivos), além de práticas de assédio moral, conforme o depoimento a seguir:

Era um setor dentro da fundição [...]. Lá tinha um supervisor. Nesse setor, devido ao ritmo acelerado de trabalho e o tipo de trabalho, gerou uma série de lesionados. Com o fim da produção, o pessoal foi sendo transferido e esse grupo com cinco pessoas passou a ser maior que o [grupo] de não lesionados. Tinha três ou quatro que não eram lesionados e o restante era lesionado. Um dia o [o supervisor] pegou esses cinco trabalhadores e trancou eles numa sala, um escritório, apagou a luz, foi lá e desligou a chave geral e trancou a porta por fora para que esses lesionados não saíssem, como se fosse um castigo. Deixou eles lá por três ou quatro horas trancados na sala. (Eduardo Oliveira Silva Carneiro, dirigente sindical, GM São José dos Campos, 24.7.2013, apud Praun, 2014, p.144-5)

Além da destruição do corpo produtivo em sua fisicidade, há também manifestações importantes de sofrimento e adoecimento psíquico decorrentes do trabalho, que são tratados com o uso de antidepressivos. O sentimento de descartabilidade e de inutilidade decorrente de adoecimentos também é recorrente, conforme o depoimento que segue:

O trabalho é importante. O trabalho é tudo. Me sinto um lixo. A empresa me usou 25 anos e depois jogou fora um bagaço. Sempre fui um bom trabalhador. (Operário 1, SJC, apud Praun, 2014, p.123)

As inúmeras Lesões por Esforço Repetitivo (LER) que afetam o corpo produtivo dos trabalhadores e trabalhadoras acabam por incapacitá-los definitivamente para o trabalho, e, na indústria automobilística, essas lesões localizam-se em maior intensidade nos membros superiores, especialmente nos ombros e na região da coluna lombar e cervical. A intensificação e a racionalização acabam por se converter em engrenagens do aumento da exploração do trabalho, que se apropria do valor criado pelo trabalho e o descarta quando sua produtividade já não mais acompanha o ritmo da produção.

\section{A agroindústria: a produção da cana}

Outro setor emblemático para a compreensão da nova morfologia do trabalho no Brasil é o da agroindústria. Vamos apresentar, então, alguns resultados da pesquisa realizada por Juliana Guanais $(2013)^{6}$ junto à agroindústria canavieira, na Usina Açucareira Ester SA, localizada em Cosmópolis, interior de São Paulo, na região de Campinas. Em 2010 a Usina possuía aproximadamente mil assalariados rurais que se dedicavam ao corte de cana.

Como o salário dos trabalhadores e das trabalhadoras está muitas vezes atrelado à quantidade de cana que é colhida diariamente, isso vem acarretando uma expressiva intensificação do trabalho, visto que a remuneração varia em 
decorrência da maior ou da menor produção diária realizada. Com esse sistema de remuneração, os empresários se beneficiam sobremaneira, uma vez que o aumento da produção também "interessa” aos trabalhadores, que querem receber mais e para tal produzem em ritmo o mais intenso possível, diferentemente do sistema de trabalho pago por jornada, em que o pagamento independe diretamente do que foi produzido. Com o desenvolvimento do processo de reestruturação produtiva do setor sucroalcooleiro, as usinas buscam tornar os trabalhadores, além de mais produtivos, também mais controlados e disciplinados em suas atividades. Foi desse modo que essa forma de pagamento - o pagamento por produção (salário por produção) - que já era utilizado por várias usinas antes da década de 1970 - tornou-se a forma de remuneração predominante no setor sucroalcooleiro.

Mas há ainda outro elemento que configura a superexploração do trabalho na agroindústria: ao cálculo do que foi produzido. Como a contabilização da produção não é feita pelos trabalhadores - e sim por funcionários das usinas -, esse cálculo tem sido um instrumento frequente de burla e redução do total produzido, recorrentemente menor do que o que foi efetivamente realizado. Os adoecimentos, as mutilações e o envelhecimento precoce passam a fazer parte do cotidiano do trabalho na agroindústria. Os depoimentos adiante ilustram essa realidade:

Eu mesma entrei nessa cobrança deles e já no primeiro mês de trabalho tive que pegar atestado porque machuquei o pulso. [...] Eu mesmo estourei o pulso... fui tentar acompanhar os outros e estourei o pulso. (Maria, trabalhadora rural)

Hoje você trabalha de empreita ${ }^{7}$ e tem regra, você tem hora de almoço e de descanso, mas ninguém tira hora de almoço... se você tirar você não ganha dinheiro... O cara acaba de comer e já vai trabalhar... uns já comem de manhã cedo e ficam o dia inteiro sem comer, toma só um cafezinho. (Osvaldo, trabalhador rural)

Como cada trabalhador recebe pela quantidade que produz diariamente, os gestores têm o controle daqueles que produzem mais, bem como dos que são considerados menos produtivos, preservando os primeiros e demitindo os segundos. A conclusão apresentada por Juliana Guanais (2013) é clara: uma vez que os salários estão vinculados à produção, os trabalhadores rurais acabam exaurindo suas energias físicas, visando produzir cada vez mais para aumentar seu salário. Isso acarreta o prolongamento de sua longa jornada de trabalho, reforçando ainda mais a superexploração do trabalho, além de reforçar a concorrência entre os trabalhadores.

A burla e a superexploração do trabalho tornam-se parte do cotidiano nos canaviais da agroindústria do etanol. A consequência acaba sendo devastadora para os trabalhadores, pois eles se tornam corresponsáveis pelo volume da produção, respondem pela intensidade que vão imprimir na produção, quantas 
pausas querem fazer e, ao fim, o quanto vão receber de salário (até quando seu corpo produtivo suportar). Além de aumentarem significativamente o lucro e a mais-valia das empresas, tem-se o aumento das doenças decorrentes do excesso de trabalho, tais as inúmeras mutilações do seu corpo produtivo, os acidentes e mortes no trabalho, traços do nosso karoshi tropical.

Esse quadro permite que a produção diária média exigida pelas empresas no corte da cana seja, então, uma fotografia real da superexploração do trabalho na agroindústria. Segundo a pesquisadora Maria A. Moraes Silva (2008), “o crescimento gigantesco dos níveis de produtividade pode ser visualizado por meio das seguintes cifras: em 1980, a média exigida no corte da cana girava em torno de 6 a 8 toneladas diárias; na década de 1990, estes números passam para 10 e a partir de 2000 , para 12 a 15 toneladas". E, se isso não bastasse, o preço de uma tonelada de cana era um pouco acima de R\$ 3 em 2010.

\section{A produção avicola}

Dentro da agroindústria, outra atividade de destaque é a produção avícola. ${ }^{8}$ A pesquisa foi realizada em uma das maiores empresas produtoras mundiais de carne de frango e derivados, em sua unidade em Toledo, estado do Paraná, onde empregava aproximadamente 6.500 funcionários e funcionava em sistema de turnos de trabalho de forma ininterrupta, 24 horas por dia durante sete dias na semana. O turno de trabalho é de $8 \mathrm{~h} 48 \mathrm{~m}$, com uma hora de almoço.

A organização do trabalho no setor é predominantemente taylorista e fordista, através de uma esteira fixa que conduz o produto a ser desossado. O ritmo do trabalho é variável, mas a média de movimentos realizados para desossar uma perna de frango (coxa mais sobrecoxa) é de 18 movimentos realizados em 15 segundos.

A temperatura ambiente é controlada entre 10 e 12 graus; a umidade e o barulho são intensos, assim como o forte cheiro que é peculiar nesse tipo de atividade. $\mathrm{O}$ resultado mais frequente é o desgaste físico e emocional dos trabalhadores e trabalhadoras, sendo frequentes os adoecimentos e os acidentes de trabalhos, conforme se constata do depoimento a seguir, ao discorrer sobre o tempo e a intensidade da produção:

No começo eram 25 segundos [o tempo exigido], agora são 20 segundos [...] A [velocidade da] esteira aumentou, o mínimo é 19 segundos, mas a gente ainda não consegue [...] (M.S., 27 anos, nove meses na empresa)

$\mathrm{O}$ adoecimento corpóreo também aflora com a fala operária:

[...] a cada 20 minutos um fica sentado, mas a maioria do tempo é em pé [...] cansa ficar sentado em cima daquelas cadeiras [...] daí começa a doer as costas [...] então o máximo que eu consegui ficar naquelas cadeiras foi uma hora [...] daí começa a dor nas costas, dor no ombro. (M.S., 27 anos, nove meses na empresa) 
Além do ritmo intenso e das condições adversas de temperatura, os operários referem-se ao sistema de metas que torna ainda mais extenuante o trabalho:

[...] tem uma meta pra ser atingida, então a nossa é no máximo seis erros que pode ter uma mesa de produção [...] a mesa inteira tem que atingir essa meta, se passar de seis erros a meta é estourada e o supervisor responde pelas anomalias. (L.D.; 20 anos, oito meses na empresa)

Combinando elementos da organização taylorista/fordista do trabalho, com um plano de metas e de envolvimento inspirado nos Círculos de Controle de Qualidade típicos do toyotismo, a avicultura tem conseguido potencializar maiores graus de exploração da força de trabalho, convivendo com o risco cotidiano de adoecimentos físicos e mentais, ajudando a configurar a nova morfologia do trabalho pautada pela precarização e pela superexploração do trabalho dentro da agroindústria.

\section{Os serviços: telemarketing e call center}

Outro setor que tem sido responsável pela significativa expansão da classe trabalhadora no Brasil encontra-se nos serviços - call center e telemarketing -, também emblemático para a compreensão da nova morfologia do trabalho no Brasil. A pesquisa foi realizada junto à Atento-Brasil, em Campinas, empresa de prestação de serviços de atendimento através de contact centers. ${ }^{9}$

A Atento iniciou suas operações em abril de 1999, na cidade de São Paulo, com pouco mais de mil funcionários. Em 2003, a empresa contava com uma equipe de 29.434 profissionais, dos quais 28.960 realizavam funções relacionadas diretamente com as operações, e em 2013 a empresa atingiu a marca de 84.131 trabalhadores/as. Para desenvolver o seu trabalho, as teleoperadoras de telemarketing (mais de $70 \%$ desse conjunto é feminino) ficam de $85 \%$ a $90 \%$ de sua carga horária diária sentadas e com atenção total ao visor do microcomputador, ao teclado e ao headset (fone de ouvido).

Conforme o depoimento da ex-teleoperadora Ignez:

[...] Eu trabalhava das 2 às 8 da noite, eu ficava 6 horas sentada, só tinha 15 minutos pra tomar café e ir ao banheiro. [...] eram 6 horas sentada recebendo ligação direto... Eu não quero ficar sentada num lugar 6 horas por dia sem você poder se movimentar.

Para controlar seu trabalho, há uma presença constante da supervisora exigindo um aumento de produtividade, através do controle do Tempo Médio Operacional (TMO) ou Tempo Médio de Atendimento (TMA), controle responsável por adoecimentos, conforme a teleoperadora Luiza nos informa:

Você tem uma meta, quando você vai passar uma informação, você fica atenta ao seu TMO (tempo médio operacional), tempo médio para passar as informações, por exemplo, eles pedem 29 segundos e tem pessoas que não querem só aquela informação, eles querem falar mais alguma coisa, então nisso você acaba atendendo mal aquela pessoa. Por exemplo, você não vai dar atenção a ela porque você sabe que o seu TMO está subindo, então, é 
isso que deixa a gente tensa no serviço. E mais, eles também ficam falando que a produtividade caiu e por isso nem a parada particular ${ }^{10}$ nós podemos fazer. Porque eles falam: gente, vamos abaixar o TMO. Vou abaixar o TMO como? As pessoas querem as informações, as pessoas não querem um robô...

A máquina, por sua vez, torna-se tão absorvente que a possibilidade da existência de relações interpessoais é quase nula. Fernanda contou que:

[...] É engraçado quando as pessoas chegam, uma olha pra cara da outra e tchau! Não dá tempo pra gente conversar. Você tem que conversar antes de entrar, porque depois que você entra não se consegue mais conversar. E, quando acaba a nossa jornada a gente está tão exausta que você entra no elevador e fala: - mais um dia; e o outro só consegue responder: - mais um dia.

Muitas empresas de telemarketing padronizaram os diálogos - os scripts e os fluxogramas de atendimento são predeterminados -, objetivando facilitar a rotinização do trabalho das teleoperadoras, através da prescrição de uma norma de comportamento que direciona inclusive a entonação da voz. E o controle das emoções da teleoperadora pela empresa é outro fator importante: a teleoperadora deve ter autocontrole, para reverter situações de agressividade que frequentemente sofrem e manter o padrão de atendimento, tanto no que se refere ao tom da fala como também ao script predeterminado.

Esse controle passa pela seguinte hierarquia: os diretores cobram os gestores (coordenadoras), que cobram as supervisoras, que por sua vez cobram as teleoperadoras, ampliando a escala de sofrimentos, constrangimentos e adoecimentos psicológicos no espaço de trabalho.

Em relação às jornadas, as operadoras trabalham 6 horas, com 15 minutos de pausa para o lanche, que são compensados no final da sua jornada, e 5 minutos de pausa particular, que é o tempo permitido para utilizar o banheiro. Conforme o depoimento da teleoperadora Luiza:

Os intervalos são pouquíssimos. São 5 minutos assim para ir ao banheiro, que eles chamam de pausa particular, e o almoço seria o intervalo de uns 15 minutos, quer dizer que quem traz comida ou coisa assim não mastiga, engole. Porque não dá. Muitas vezes eu não consigo fazer a pausa particular, eu tento conter, mas têm pessoas que não conseguem, porque têm esse negócio de retenção urinária ou que toma remédio. Então é difícil ... Eles lá não têm respeito, têm pessoas que precisam ir ao banheiro e não podem...

Além desses mecanismos de controle, há também ações contra os atrasos e o absenteísmo no trabalho, através de campanhas desenvolvidas pela empresa para incentivar a disciplina das teleoperadoras. E outro elemento importante, na visão patronal, é estabelecido pelas campanhas que estimulam a produtividade. Elas são conhecidas como um "incentivo motivacional" para estimular a competitividade, tendo como objetivo aumentar a produtividade através da intensificação do ritmo de trabalho. 
Os adoecimentos tornam-se, então, rotineiros no telemarketing, causados pelos ruídos, pelo mobiliário, pelo espaço físico etc. O depoimento a seguir confirma esse problema:

O problema que eu tenho é do braço. Ele dói muito, principalmente quando o tempo muda, mas isso aconteceu de tanto eu fazer esforço repetitivo. Eu já fui no médico, ele ainda não disse que é LER/DORT, essas coisas, ele falou para fazer a fisioterapia, mas eu não consigo marcar a fisioterapia porque não tem vaga, aí tem que ficar na fila e só tem em dois hospitais da cidade. E, aí eu continuo fazendo o meu trabalho e vai piorando cada vez mais. Ele (o médico) nem pediu uma licença médica para mim, o que ele passou foi só injeção e pronto. Eu já até tomei as cinco injeções e aliviou a dor. Só que volta tudo de novo.

Embora a pesquisa apresente inúmeros outros resultados, deve-se acrescentar que na unidade da Atento, em Campinas, de um contingente de 1.863 trabalhadores (396 são homens e 1.467 são mulheres), encontravam-se afastados do trabalho por doença ou acidente de trabalho cerca de 136 funcionários (aproximadamente $7,5 \%$ do total), e ainda desse total, somente seis $(1,5 \%)$ eram do sexo masculino.

Podemos afirmar, então, que o trabalho de telemarketing e call center é pautado pela exploração intensificada, visando atingir as metas de produtividade, dentro dos tempos e padrões impostos pela empresa. Para além de seus objetivos aparentes, quais sejam, "garantir a qualidade dos atendimentos" e a "satisfação do cliente", as operadoras de telemarketing vivem um significativo processo de exploração da sua força de trabalho, visível quando se pesquisam as suas condições de saúde, tempo, "qualidade", "motivação", dentre tantos elementos presentes em seu cotidiano.

Vale acrescentar que $96 \%$ das centrais de telemarketing e call center foram criadas após 1990, e especialmente depois da privatização do sistema Telebras, em 1998. Como se trata de uma modalidade de emprego que tem baixa qualificação da força de trabalho e pouca experiência de atuação dos sindicatos, segundo Ruy Braga (2014), os seus salários estão entre os mais baixos do mundo, superando apenas os salários dos trabalhadores indianos. ${ }^{11}$ Segundo a Associação Brasileira de Telesserviços (ABT), estimava-se que, em 2012, mais de 1,4 milhão de trabalhadores encontravam-se empregados no setor. E, desse contingente, grande parcela é oriunda dos jovens e mulheres, e as empresas Atento e Contax são as maiores do setor no Brasil (ibidem).

As exigências de metas, a rotinização do trabalho, o despotismo dos coordenadores e supervisores, os baixos salários, os adoecimentos e padecimentos decorrentes das condições de trabalho são traços constitutivos desse novo proletariado de serviços que está em expansão no Brasil e em várias partes do mundo, dada a importância das informações para o capitalismo financeiro global. Constituem-se, portanto, uma nova parcela que amplia e diversifica a classe trabalhadora no Brasil. 


\section{Uma breve conclusão}

Contrariamente às teses que advogam a perda de relevância do trabalho no mundo contemporâneo, estamos desafiados a compreender sua nova morfologia, cujo elemento mais visível é o seu desenho multifacetado, resultado das fortes mutações que afetaram o capitalismo nas últimas décadas. Nova morfologia que, no Brasil, compreende desde o operariado industrial e rural, até os assalariados de serviços, os novos contingentes de homens e mulheres terceirizados, subcontratados, temporários que se ampliam. Nova morfologia que presencia a ampliação de novos proletários do mundo industrial, de serviços e da agroindústria, de que são exemplos as trabalhadoras de telemarketing e call center, das tecnologias de informação e comunicação que se desenvolvem na era digital, além dos digitalizadores que laboram nos bancos, dos assalariados do fast food, dos trabalhadores jovens dos hipermercados, dos motoboys que morrem nas ruas e avenidas, usando suas motocicletas para transportar mercadorias etc. E essas distintas modalidades de trabalho vêm desempenhando um papel de destaque, não só na agilização da circulação de informações, vital para a reprodução do capital, como também no desencadeamento de novas lutas sociais e sindicais.

À guisa, portanto, de conclusão, procuramos apresentar neste artigo um desenho da classe trabalhadora brasileira que engloba o conjunto dos assalariados, homens e mulheres que vivem da venda de sua força de trabalho em troca de salário, na indústria, na agricultura e nos serviços, bem como nas interconexões existentes entre esses setores, como na agroindústria, nos serviços industriais, na indústria de serviços etc.

Em um sentido ampliado, a classe trabalhadora deve incorporar tanto os/ as trabalhadores/as produtivos/as, que agregam diretamente valor, como também o amplo conjunto de assalariados improdutivos, que não geram diretamente mais-valia, mas que são imprescindíveis nesse processo de trabalho capitalista e que vivenciam, tanto objetiva quanto subjetivamente, situações que têm clara similitude com aquelas experimentadas pelos trabalhadores produtivos. Embora ela tenha como núcleo central os trabalhadores produtivos, a classe trabalhadora abrange também, em nosso entendimento, os trabalhadores improdutivos, que não criam mais-valia, mas que são imprescindíveis para a criação de valor e parte constitutiva do conjunto dos assalariados (Antunes, 2010).

A partir das profundas transformações ocorridas no mundo produtivo do capitalismo contemporâneo, o conceito ampliado de classe trabalhadora não deve se restringir somente aos trabalhadores manuais diretos, mas deve incorporar a totalidade dos trabalhadores e trabalhadoras, cada vez mais integrados pelas cadeias produtivas globais, que vendem sua força de trabalho como mercadoria em troca de salário e são pagos por capital-dinheiro, independentemente de a atividade que realizam ser predominantemente material ou imaterial. E no capitalismo financeirizado da era informacional, desenvolve-se cada vez mais uma simbiose entre o que é produtivo e o que é improdutivo, uma vez que o mesmo 
trabalho executa frequentemente atividades que geram valor e, simultaneamente, conferem a qualidade do que realizaram.

Pelo desenho empírico que oferecemos ao longo deste artigo, acrescentamos que tanto os assalariados da indústria quanto os da agroindústria e do setor de telemarketing e call center são partes constitutivas das forças sociais do trabalho que participam, direta ou indiretamente, da geração de mais-valia e da valorização do capital. Oscilando entre a grande heterogeneidade em sua forma de ser (gênero, etnia, geração, espaço, qualificação, nacionalidade etc.) e a impulsão tendencial para uma forte homegeneização que resulta da condição precarizada presente em distintas modalidades de trabalho que se ampliam em várias partes do mundo e também no Brasil, eles se convertem cada vez mais em partícipes ativos no desencadeamento de novas lutas sociais e sindicais que vêm se ampliando em escala global.

\section{Notas}

1 Usaremos sempre a noção de trabalhadores contemplando sua dimensão de gênero, como trabalhadores e trabalhadoras, uma vez que há uma clara divisão sociossexual do trabalho, frequentemente desigual e diferenciada. Assim, sempre que usarmos trabalhadores, ao longo deste artigo, esclarecemos nesta nota que o concebemos também em sua dimensão de gênero, como trabalhadores e trabalhadoras.

2 Segundo Pochmann (2012, p.27), “foram criados 11 milhões de empregos, dos quais $53,6 \%$ do total eram sem remuneração. Na faixa de renda de até 1,5 salário mínimo houve a redução líquida de quase 300 mil postos de trabalho".

3 Todas as informações de pesquisa que constam neste item são resultado do projeto coletivo de pesquisa, em que foram pesquisados os mais diferenciados ramos e setores da economia e que foram publicados em Riqueza e miséria do trabalho no Brasil, v. I, e III (Antunes, 2006, 2013, 2014).

4 Todas as informações referentes à General Motors (GM) foram pesquisadas e redigidas por Luci Praun (2014), pesquisadora de nosso Grupo de Pesquisa “As Metamorfoses do Mundo do Trabalho" (Unicamp/CNPq) e constam de sua tese de doutorado Não sois máquina! Reestruturação produtiva e adoecimento na GM do Brasil, defendida no IFCH/Unicamp, sob orientação do Prof. Ricardo Antunes. A redação final deste subitem, feita a partir do texto original da pesquisadora, é de responsabilidade de Ricardo Antunes.

5 A GM possui no Brasil três complexos industriais voltados à produção de automóveis: o de São Caetano do Sul, em operação desde 1930; o de São José dos Campos, inaugurado em 1959; e o de Gravataí/RS, organizado desde o início de suas atividades, em 2000, sob o modelo de Consórcio Modular.

6 As informações que constam neste subitem foram pesquisados por Juliana Guanais (2013), pesquisadora de nosso Grupo de Pesquisa “As Metamorfoses do Mundo do Trabalho" (Unicamp/CNPq) e estão publicados em Riqueza e miséria do trabalho no Brasil, v.II (p.305-23). A redação final deste subitem, feita a partir do texto original da pesquisadora, é de responsabilidade de Ricardo Antunes.

7 “Trabalhar de empreita” é sinônimo de trabalhar por produção. 
8 As informações que constam neste item foram pesquisados por Vera Navarro e Marcos Neli (2006), pesquisadores vinculados ao Grupo de Pesquisa "As Metamorfoses do Mundo do Trabalho" (Unicamp/CNPq) e estão publicados em Riqueza e miséria do trabalho no Brasil, v.II (p.287-304). A redação final deste subitem, feita a partir do texto original da pesquisadora, é de responsabilidade de Ricardo Antunes.

9 As informações que constam neste subitem foram pesquisadas por Claudia Mazzei Nogueira (2006), pesquisadora vinculada ao Grupo de Pesquisa “As Metamorfoses do Mundo do Trabalho" (Unicamp/CNPq) e estão publicados em Riqueza e miséria do trabalho no Brasil, v.I (p.269-95). A pesquisa foi publicada no livro $O$ trabalho $d u$ plicado (Nogueira, 2011) e atualizada em 2014. A redação final deste subitem, feita a partir do texto original da pesquisadora, é de responsabilidade de Ricardo Antunes.

10 Parada particular são os cinco minutos que a teleoperadora tem para ir ao banheiro dentro de uma jornada de trabalho de seis horas.

11 Conforme a pesquisa de Ruy Braga (2014), que será publicada em Riqueza e miséria do trabalho no Brasil, v.III (no prelo). Ver também Antunes e Braga (2009).

\section{Referências}

ALVES, G. O novo (e precário) mundo do trabalho. São Paulo: Boitempo, 2000.

ANTUNES, R. (Org.) Riqueza e miséria do trabalho. São Paulo: Boitempo, 2006. v.I. . Os sentidos do trabalho. 11 .reimp. São Paulo: Boitempo, 2010. . (Org.) Riqueza e miséria do trabalho. São Paulo: Boitempo, 2013. v.II. . (Org.) Riqueza e miséria do trabalho. São Paulo: Boitempo, 2014. v.III (no prelo)

ANTUNES, R.; BRAGA, R. Infoproletários (Degradação real do trabalho virtual). São Paulo: Boitempo, 2009.

BRAGA, R. A formação do precariado pós-fordista no Brasil, In: ANTUNES, R. (Org.) Riqueza e miséria do trabalho. São Paulo: Boitempo, 2014. v.III (no prelo).

DRUCK, G. Terceirização: desfordizando a fábrica - um estudo do complexo petroquímico da Bahia. São Paulo: Boitempo; Edufba, 1999.

2011. . Trabalho, precarização e resistências. Caderno CRH (UFBA), Salvador, v.24,

DRUCK, G.; FRANCO, T. Terceirização e precarização: o binômio antissocial em indústrias. In: _... (Org.) A perda da razão social do trabalho: precarização e terceirização. São Paulo: Boitempo, 2007.

GUANAIS, J. Quanto mais se corta, mais se ganha. In: ANTUNES, R. (Org.) Riqueza e miséria do trabalho. São Paulo: Boitempo, 2013. v.II.

HUWS, U. The making of a cybertariat (Virtual work in a real world). New York; London: Monthly Review Press; The Merlin Press, 2003.

NAVARRO, V.; NELI, M. Reestruturação produtiva e saúde do trabalhador na agroindústria avícola do Brasil. In: ANTUNES, R. (Org.) Riqueza e miséria do trabalho. São Paulo: Boitempo, 2006. v.I. 
NOGUEIRA, C. A feminização do trabalho no mundo do telemarketing. In: ANTUNES, R. (Org.) Riqueza e miséria do trabalho. São Paulo: Boitempo, 2006. v.I.

O trabalho duplicado. São Paulo: Expressão Popular, 2011.

POCHMANN, M. Nova classe média? O trabalho na base da pirâmide social brasileira. São Paulo: Boitempo, 2012.

PRAUN, L. Não sois máquina! Reestruturação produtiva e adoecimento na General Motors do Brasil. 2014. Tese (Doutorado) - Instituto de Filosofia e Ciências Humanas, Universidade de Campinas. Campinas, 2014.

SILVA, M. M. Trabalhadores rurais: a negação dos direitos. Raízes, Campina Grande, v.27, n.1, jan./jun. 2008.

RESUMO - O objetivo deste artigo é apresentar algumas tendências presentes no mundo do trabalho no Brasil recente. Se até a década de 1980, por exemplo, era relativamente pequeno o número de trabalhadores terceirizados, nas décadas seguintes houve um aumento significativo, resultado do forte processo de reestruturação produtiva e das mudanças no espaço da organização sociotécnica do trabalho. Pretendemos indicar, em seguida, um desenho de três setores que cumprem papel de destaque no capitalismo brasileiro: a indústria automobilística, a agroindústria e o telemarketing e call center. Assim, esperamos indicar alguns traços constitutivos da nova morfologia do trabalho no Brasil.

PALAVRAS-CHAVE: Nova morfologia do trabalho, Classe trabalhadora, Trabalho, Indústria, Agroindústria, Serviços.

ABSTRACT - This paper examines some recent trends in the world of labor in Brazil. For instance, until the 1980s, the number of outsourced workers was relatively small, whereas the following decades saw a significant increase in their number, resulting from a powerful restructuring of production processes and from changes in the realm of the socio-technical organization of work. We also intend to outline three sectors that play an important role in Brazilian capitalism: the auto industry, agribusiness, and telemarketing and call centers. We thus hope to indicate some constitutive features of the new morphology of labor in Brazil.

KEYWORDS: New morphology of labor, Working class, Labor, Industry, Agribusiness, Services.

Ricardo Antunes é professor titular de Sociologia do Trabalho na Universidade Estadual de Campinas (Unicamp). Autor, entre outros livros, de Os sentidos do trabalho (Boitempo, 2010); Adeus ao trabalho? (Cortez, 2014) e organizador de Riqueza e miséria do trabalho no Brasil, v.I e II (Boitempo, 2006 e 2013), e pesquisador do CNPq. @ - rantunes@unicamp.br

Recebido em 18.6.2014 e aceito em 28.6.2014.

I Universidade Estadual de Campinas. Campinas/SP, Brasil. 